\title{
Perspektif dan Pendekatan Teori Manajemen yang telah berkembang Sepanjang Sejarah
}

\author{
${ }^{1}$ Gilang Maulana, ${ }^{2}$ Kasful Anwar US \\ 1-2 Fakultas Ekonomi dan Bisnis Islam, Universitas Islam Negeri Sultah Thaha Saifuddin Jambi
}

Article history

Received. : 10 July 2021

Revised. : 26 July 2021

Accepted : 15 September 2021

*Corresponding Author: Gilang Maulana

Fakultas Ekonomi dan Bisnis Islam, Universitas Islam Negeri Sultah Thaha Saifuddin Jambi Email: gilangmlna8@gmail.com

\begin{abstract}
Theory is a thing that is seen as monotonous and hinders fieldwork for people who are used to the field, but the real purpose of theory is to determine the professional nature of workers, just as management theory is needed to manage worker activities in order to get work agreements. which is good and does not burden one side, both from the workers and the company. This journal contains the stages of development of management theory in the world, compiled based on references that are owned even though they are limited
\end{abstract}

Keywords: Management, Workers, Professionalism

\section{PENDAHULUAN}

Setiap teori tentunya mengalami perkembangan, termausk juga teori menejemen yang sejauh ini justru memiliki dampak baik dalam prosesi manajemen yang menyelaraskan anatara teoritisi dan praktisi manajemen yang membuahkan hasil yang luar biasa. Ada beberapa pertanyaan yang sering muncul dalam pembahasn teori teori, dalah satunya mengapa kita harus memahami dasr dan membuthkan teori ? pertanyaan sejenis ini biasanya timbul dari oang orang yang sudah terjun ke dunia pratktik. Memang, tanpa teori merka sudah bisa sukses dan teori hanya teresan sebagai hal yang hanya memperlambat kerjaanya. Hanya saja, merke atidak menyadaro sepenuhnya bahwa teori menjadikan mereka lebih berfantasi dan membayangkan hal yang lebih dari yang bisa di bayangkan dan otak mereka terangsang untuk mewujudkan itu dengan cara yang gila. Sehingga teori sejatinya membawa kontribusi yang penting dalam hal praktik, nilaman aini di pahami dengan benar. Perkembangan teori teori manajemen, terori keuangan dan lainnya sebenarnya merupakan bukti bahwa teori ini memiliki dampak dan kontribusi dalam perkembangan dunia. Sederhaanya, lahirnya ekolah sekolah manajemen dan sejenisnya merupakan bukti lain yang sangat bermanfaat dari yang dimaksudkan.

Pengertain teori dapat di pahami sebagai kumpulan prinsip prinsip yang di susun pengamat dengan secara sistematis, prinsip ini berusaha menjelaskan hubungan antara fenomena dan kejadian nyata yang ada dan membuat kesimpulan atasnya. Keseimbangan natara pemikiran dan hal yang sebanarnya terjadi dan menimbulkan perspektif yang benar 
dan terakui serta teruji. Dengan hal ini tentunya kana ada pengamatan lebih lanju tuntuk terus memperbaharui teori, sampai ada yang dapat menjealskan dan merubah teori itu sebagai satu perkembangan dengan hasil yang berbeda dengan bukti yang setara dengan penelitian sebelumnya dan tidak dapat di bantah. Adalah sebauah hal yang pasti manakla setiap teori kemudan mengembangkan konsep konsep yang di adposi dari fenmena yang teliti dan memberikan informasi dan masukan yang dibutuhkan untuk masa yang akan datang.

Secara sederhananya, teori yang akan di bahas yakni teori manajemen bisa membantu memajukan praktik manajemen dan memberikan dobrakan baru dalam kegiatan belajar ini dan membicarakan perkembangan terosinya yang meliputi : teori manajemen kuno, teori manajemen klasik, aliran perilaku, aliran kuantitatif, dan teori menjemene kontemporer.

\section{METODE PENELITIAN}

Penelitian ini menggunakan penelitian kualitatif dengan metode studi literatur. Penelitian kualitatif yaitu memahami dan menafsirkan makna dari suatu data menurut perspektif peneliti sendiri. Penelitian menggunakan metode studi literatur yaitu meneliti dan memahami buku-buku, jurnal, artikel, karya ilmiah dan sumber dokumen tertulis lainnya yang relevan dengan topik pembahasan. Hasil dari berbagai telaah literatur ini akan digunakan untuk mengidentifikasi pengaruh usia sumber daya manusia pada koperasi.

\section{HASIL DAN PEMBAHASAN}

\section{A. Teori Manajemen Kuno}

Manajemen sejatinya sudah di gunakan sejak zaman dahulu meski dalam praktik terdahulu belum menggunakan manajemen dalam bentuk teori atau bisa di katakana belum di rumuskan secara sistematis dan komprehensif. Manjemen hadir dan lahir sejalan dengan munculnya peradaban manusia. bisa diangkat sebagai contoh, kekaisaran romawi mengembangkan struktur organisasi dan koordinasi yang baik yang jelas sangat membantu komunikasi dan pengadilan. Konsep konsep menajemen juga sering dibicarakan oleh filsuf Yunani atau Arab (Islam) pada Abad Pertengahan.

1) Mesir Kuno

Peradaban Mesir Kuno menghasilkan warisan yang luar biasa yakni piradmida, yakni sebuah abngunan yang mungkin sangat terkenal dan menajdi ikon negara mesir. Sebagai bangunan yang sangat besar dan luas, dalam pengerjaan pembangunan satu piramida melibatkan lebih dari 100 ribu orang dalam kurun waktu tidak kurang dari 20 tahun. Dalam mengkontruksikan pembangunan piramida ini jeals membutuhkan manajemen yang mengatur dan menentukan segalanya, pasti ada manajer yang bertugas merencanakan, mengorganiasasikan, mngekoordinasikan dan mengendalikan aktivitas manusia, sumber daya dan segala elemen yang di butuhkan dalam pembanguanna agar piramida tersebut bida kokoh berdiri tanpa ada kecacatan.

2) Machiavelli

Italia sebagai sebuah negara yang sangat maju memiliki seorang pemikir handal yang merumuskan beberapa prinsip manajemen dalam bukunya yang berjudul : Disciurses yang di tulis pad atahun 1531. Ia merumuskan dan meuliskan beberapa prinsip yang relavan dan sejalan dengan manajemen kontemporer yakni :

a) Organisasi akan lebih stabil jika anggotanya mempunyai kebebasan untuk mengemukakan perbedaan dan memecahkan onflik tersebut dalam organisasi

b) Satu orang bisa mendirikan organisasi, tetapi organisasi akan lebih bertahan lama jika menjadi urusan banyak orang dan ketika orang orang tersebut ingin mempertahankan organisasi tersebut. 
c) Menejer yang lemah bisa memgang wewenang dengan mengikuti menjeer yang kuat, tetapi tidak mengikuti manajer yang lemah lainnya.

d) Manajer yang ingin mengubah organisasi yang mapan harus mempertahankan setidaknya warisan organisasi lama "bayangan" (a asahdow of the ancient customs)

3) Sun Tzu

Sun Tzu, seorang Filsuf China yang hiduo sekitar 2000 tahun yang lalu menurlis sebuah buku yang berjduul : The Art of Wars (Seni Perang). Beberapa prinsip yang di kembangkannya yakni :

a) Jika musuh maju, kita mundur

b) Jika musuh berhenti, kita memprovokasi

c) Jika musuh berusaha menghindari perang, kita menyerang

d) Jika musuh mundur, kita kejar

Yang dimana meskipun prinsip ini di tuliskan dan di ajarkan dalam erumpamaan perang, kita dapat mengadaptasinya dalam konteks bisnis sebagai strategi bisnis daklam tingkaatan tertentu

\section{4) Adam Smith}

Adam Smith merupakan seorang ekonim klasik yang hidup pada abad ke 18. Dimana pada tahun 1776 ia mempublikasikan sebuah karya tulisannya yang di bukukan dengan judul The Wealth of Nations, yang didalam bukunya ini Adam Smith berpendapat bahwa masyarakat seharusnya melakukan pembagian tenaga kerja (devision of labor) aau spesialisasi kejra (jon specialization). Menurut Adam Smith, suatu tugas bisa dipecah pecah ke dalam bagian yang kecil. Setlahnya tugas itu bisa di kembangkan dan kerjakan berulang ulang sehingga orang yang dibidang itu sangat terbiasa dan menjadi ahli spesialis. Hal ini bisa berakibat orang yang menjalaninya memiliki ketelitian dan tingkat produktivitas yang mumpuni. Terosi sepsialis ini membuka pikiran banyak jalangan termasuk pemikir filsuf manajemen yang hidup semasa dan setelah masa Adam Smith.

\section{B. Teori Manajemen Klasik}

1) Robert Owen (1771-1858)

Dimulai pada tahun 1800-an sebagai manaejer pabrik pemintalan kapas di New Lnark, Skotlandia. Robert Owen memberikan perhatian khususnya pada penggunaan faktpr produki mesin dan factor profuksi tenaga kerja dan dari hasil pengamatannya ia menyimpulkan bahwa bilamana suatu mesin diberikan perawatan yang baik maka akan memberikan keuntngan pada perusahaan dan sama halnya dengan tenaga kerja, hika tenag akerjad di perlihata dan di beri perlakuan yang baik (perhatian yang cukup, kompensasi yang memadai, tunjangan kesehatan dan tunjangan lainnya) oleh pimpinan lapangan maupun pimpinan kerusahaan yang mendapakan keuntungan dari kehadiran mereka. Ia menilai bahwa dua hal ini merupakan asset penting bagi perusahaan yang dengan adanya mereka inilah perusahaan dapat berkembang melalui hasil produksi.

Kemduian ia menyatakan bahwa kuantitas dan kualitas hasil pekerjaan dipangaruhi oleh situasi eksternal dan internal dari pekerjaan.ia memperkenalkan sistem penilaian terbuka ini dan di alkukan setiap hari, dengan begini ia berharap bisa melokalisasi masalahan yanga da dengan cepat dan cara ini juga membuat pekerja yang memiliki andil besar merasa bangga karena dikenalkan dan disebut Namanya sebagai pekerja teladan yang menjadi feedback di masa berikutnya. Atas hasil penelitian Robert Owen yang di kenal sebagai Bapak Manajemen Peronalia, ia juga sebagai salah seorang pendiri Gerakan koperasi konsumsi. Adapun usaha yang pernah ia lakukan dan mengalami keagaglan ialah mendirikan sebuah komunitas di New Harmoni, Indiana pada tahun 1824.

2) Charles Bobbage (1792 - 1871)

Babbage merupakan seorang professor Matematika di Inggris, yang dengan latar 
belakang pendidikan kuantitatifnya ia menaruh perhatian dan minat ada bidang manajemen dan percayabahwa prinsip rinsip ilmiah yang dapat di terapkan untuk meningktakan efisiensi produksi, productivitas naik dan biaya operasi turun. Dia emnganjurkan gar para manajer bertukar pengalaman dan penerapan prinsip prinsip manajemen. Kontribusinya terlihat dari terbitnua buku Pn the economy od machinery and manufactures. Ia menganjurkan pembagian kerja sehingga kerja setiap pabriknya bisa di analisis secara terpisah. Dia percyaa bahwa metode kauantitatid bisa digunakan untuk menganalisis perosalan perusahaan seperti untuk mengefeisenskan penggunaan bahan baku dan fasilitas lain karena pekerja dalam sub bidang pekerjaan ini lebih paham dan mengerti. Dengan hal inilah Bobbage disebut pioneer manajemen ilmiah.

Adapun kelebihan yang di miliki oleh hal pembagian kerja ini ialah :

a) Waktu yang di perlukan untuk belajar dari pengalaman pengalaman yang baru

b) Banyaknya waktu yang terbuang bila seseorang berpindah dari satu pekerjaan ke permukaan lain, dan orang tersebut harus di sesuaikan kembali pada pekerjaan baru hinga akan menghamabt kemajuan dan keterampilan pekerja, untuk itu di perlukan spesialisai dalam pekerjaannya.

c) Kecapakan dan keahlian seseorang bertambah karea seorang pekerja bekerja terus menerus dalam tugaasya

d) Daya perhatian pada pekerjaannya sehingga dapat meresapi alat alatnya karena perhatiann

Charles Babbage menciptakan mesin hitung yakni calculator sebagai alat mekanis pertama dan mengembangan program permainan untuk computer, mengembangkan kerja sama yang saling menguntungkan antara para pekerja dengan pemilik perusahaan, serta membuat skema perencanaan pembagian keuntungan.

\section{Teori Manajemen Ilmiah}

1) Fredrick Winslow Taylor (1856-1951)

Manajemen ilmiah atau manajemen yang menggunakan ilmu pengetahuan muali di bahas sekitar tahun 1900an, tFredrick Winslow Taylor atau yang lebih akrab di sapa Taylor asalah seorang manaje dan penasihat perusahaan serta merupakan seorang tokoh besar manajemen yang di kenal sebagai bapak manajemen ilmiah atau scietifick menegement. Taylor memberika perhatian khusus pada studi waktu untuk setiap pekerjaan (time anad motion study). Pada sebuah pabrik baja di Philadelphia, ia melihat pekerja yang mealkukan Teknik soldering sengaja memperlambat pekerjaannya dengan lebih rendah bila di bandingkan dengan kemampuan yang sebenarnya hal ini di analisis oleh Taylor dan untuk hal itu Taylor mengusulkan bahwa pekerja dan pekerjaan di pecah dalam kelompok kelompok kecil dan diberikan waktu yang ditentukan untuk bisa di gunakan pekejra dengan baik dengan menggunakan cara kerja yang baik dan dipealajari. Taylor kemudian juag memperkenakan sistem pembayaran differential rate system, yang dimana dengan cara tersebut karyawan akan memperoleh kenaikan upah apabila berhasil melampaui standai yang telah di tentukan. Kenaikan upah tersebut dihitung secara terliti berdasrakan perkiraan kenaikan keuntungan perusahaan karena kenaikan produksi tersebut. Jadi dengan begitu baik perusahaan dan tenaga kerja saling memperoleh keuntungan.

Karena teorinya itulah Taylor di angkat menjadi konsultan di beberpaa perusaha, dan dengan cara tersebut merasa dapat mengimplementasikan idenya dengan lebih efektif dan melaporkan banyak perusahaan yang suskes dengan menerapkan metodenya dengan teoru. Namun, meskipun sukses menaikkan produktivtas, banyak tentangan yang muncul seperti pekerja mulai takut diberhentikan apabila oerusahan menggunakan metode yang di kembangkannya, tantangan tersebut enyeabkan pemogokan beberapa pabrik yang berakibat 
Taylor di panggil oleh Wakil Rakyat di Amerika Serikat guna menjealaskan teori menegenai ide idenya, dan penjelasan itu ditulsikan dalam tiga makalah yakni : Shop Management, The Principle of Scientific Management dan Testimory before the Spesial House Commite, yang selanjutnay di eangkum dalam sbeuah buku berjudul Scientific Management yang di terbitkan pertama kali oleh Da Mounth Collage, Hannover pada 1911.

Taylor mengemukakan beberapa prinsip manajemen ilmiah sebagai bentuk langkah langkah, yaitu :

a) Mengembangkan ilmu pengetahuan untuk setiap elemen pekerjaan dan untuk menggantian metode perkiraan yang tanpa di dasari ilmu

b) Memilih karyawan secara ilmiah dan melatih mereka untuk melakukan pekerjaan seperti yang telah di tentukan pada langkah pertama

c) Mengawasi karyawan untuk memastian merka mengkuti metode yang telah ditentukan untuk mengerjalan uatu pekerjaan speerti langkah pertama. Pengawasan dilakukan secara ilmiah

d) Kerja sama anatra manajemen dan pekerja di tingkatkan, persahabatan antara keduanya juga di tingkatkan.

Adalah sebuah hal yang menarik dari pendapat Ttaylor yang mendeklarasikan bahwa manager merupakan pelayan bagi bahwannya yang sebenarnya bertentangan dengan pendapat sebelumnya yang mengatakan bahwa bawahan adalah pelayan manager. Taylor mengatakan bahwa Scientif manaejmen merupakan sebuah tugas untuk memberikan yang terbaik dari yang baik melalui pengalisaan, observasi dan percobaa percobaan yang diberi nama studi gerak dan waktu. Dan observasi lainnya yakni sistem organisasi yang di berinama organisasi fungsional yang bergai menjadi dua bagian yakni pagian perencaan dan bagian pelaksanaan.

Taylor menyebutkan bahwa agar prinsip terebut dapat sukses secara keseluruham diperlukan revolusi mental yang meneylutuh baik dari sisi manajemen maupun diri pekerja dengan berfokus pada peningkatan produktivitas dan keuntungan agar lebih besar, yang keuntugan ini tentu akan membawa keuntungan bagi selutruh pihak dan tidak ada yang memiliki peranan yang lebih penting, semunanya memiiki kepentingan yang sama.

2) Frank B. Gilberth (1868-1924) dan Lilian Gilberth (1878-1972)

Kedua tokoh ini adalah sepasang suami istri yang memiliki minat yang sama terhadap manajemen dan berkecimpung serta bersama mengembangkan menjemen ilmiah. Frank Gilbert melakukan studi pekerjaan tukang batu dalam melakukan tiga hal yakni mengaajar tukang batu baru, cara bekerja cepat dan sengaja memperlambat kerjannya. Setlah itu ia melakukan studi mengenai pengajuan metide kejr ayang efisien dan menguangi pekerjaan fisik dan meningktakan output hingga 300\% dan sukses mengerahkannya pada studi gerak dan kelelahan. Ia berpendapat pergerakan yang dapat dihilangkan akan mengurangi kelelahan. Semangat kerj ayang naik akan bermanfaat secara fisik pada karyawan. Sedangkan sitrinya, Lilian Gilberth, memberian kontribudi yang cukup luas pada psikologi industry dan manajemen personalia. Ia sangat yakin akan tujuan akhir manajemen ilmuah yang akan membantu perkeja mencapai potensi sepenuhnya sebagai manusia.

3) Henry L. Gantt (1861-1919)

Gantt sebelumnya merupakan asisen Taylor, kemudian ia bekerja sendiri sebagai seorang konsultan dan melakukan perbaikan metode Taylor. Dia melakukan perbaikan atas pengajian taylor karena menurutnya metode tersebut kurang berdampak pada motivasi kerja pekerja untuk meningkatkan produktivitas kerjanya.

Setelahnya Gantt memperkenalkan sistem penilaian terbuka yang semulanya ialah ide Owen. Kemajuan pekerjad I catatan dengan baik dengan kotak warna hitam sebagai bentuk pemenuhan standard dan warna merah sebagai bentuk tidak memenuhi standar. Yang dimana bagan ini menajdi popular dan digunakan untuk perencanaan jadwal pekerjaan 
tertantu.

Adapun gagasan yang di cetuskan oleh Gantt dalam teorinya ialah :

a) Kejra sama yang saling menguntungkan antara manajer dan teanga kerja untuk mencapai tujuan bersama

b) Mengadakan seleksi ilmuah terhadao tenaga kerja

c) Membayar upah pengawai dengan menggunakan sistem bonus

d) Penggunaan instruksi kerja yang terperinci

\section{Kelebihan dan Kelemahan Teori Manaejmeen Ilmiah}

Teori manajemen ilmiah memberikan masukan penting. seperti produksi massal yang merupakan implementasi dari terori manejemen ilmiah, barang yang di prosuksi ceoat dan sebanyak banyaknya. Proses produksi sejenis ini cukup efisien. Ide massalisasi semacam itu bahkan mempengaruhi sektoe lainnya seperti bidang jasa. Manajemen lmiah mendorong pendekatan rasional untuk memecahkan maslaah, dan pendekatan semacam ini merangsang pendekatan ilmiah dalam manejemen dan mendorong pendekatan manajemen sebagai ilmu dan menyebabkan profesionalsime manajemen. Teri manejmen ilmiah tetap saja memiliki keterbatsasn yakni asumsi atau pendapat bahwa manusia sebagai sumber daya atau pekerja akan berusaha emmenuhi keutuhan ekonomi dan fisiknya tidak selalu benar. Tujuan produktivitas yang di cari ialah keuntungan semata yang venderung menagrah pada ekspolitasi pekerja. Asumsi yang global menegnai pendekatan menejemen ilmiah ini bahwa maenjemen dapat di pakai di semua situasi dan di semua tempat tidak peneuhnya tepat. Hal ini bida terjadi karena adanya beberapa pendekatan yang cocok untuk waktu dan tempat tertentu yapi mungkin bsia tidak cocok atau waktu dan tempat yang lain.

\section{a. Teori Organisasi Klasik}

Teori adminitrasi klasik menfokuskan upaya peningkatan produktivitas yang mengerucutkan pada kebutuahan estimasi can cara pengelolaan organisasi yang semakin kompleks.

\section{1) Henry Fayol (1841-1925)}

Tokoh satu ini merupakan industrialis Prancis yang serinf di sebut sebagai bapak aliran menjemeen jalsik karena upayanya dalam membauat estimasi studi menjerial. Pokok pikirannya ditulis dalam satu buku yang berjudul General adna Industrial Management. Menurtunya, praktik managemen f-itu dapat di bagi dalam beberpaa pola yang diidentifikasikan dan di analisis. Setelahnya analisis itu dapat di ajarkan keapda manajer lain atau calon manajer. Fayol membagi kegiatan bisnis menjadi enam kegiatan pokok yang saling berkaitan, yakni :

(1) Tenis - memproduksi produk

(2) Komersial - membeli bahan baku dan menjual produk

(3) Keuangan - mencari dan menggunakan dana

(4) Keamanan - menjaga karyawan dan keamanan perusahaan

(5) Akuntasi - mencatat dan mengukur transaksi

(6) Manaejemn

Dan dari keenam kegiatan itu, Fayol mengerucutkannya menajdi kelompok manajerial yakni (1) Perencanaan, (2) Pengorganisasian (3) pengarahan dan (4) pengendalian.

Henry Fayol mengemukakan 14 prinsip menjemen, yakni :

a. Devision of work (pembagian kerja) : spesialisasi membuat kerja dan pekerjaan terlihat lebih efeisien

b. Uathority and Resonsibility (Wewenang) : manajer harus memberikan perintah agar bida di kerjakan dan kekuasan untuk dipatuhi, kewenangan terbagi menajdi 
dua yakni wewneang personal yang bersumber dari intelegensia, dan wewenang resmi yang di terman dari wewenang yang berada did atasnya.

c. Dicipline (Disimplin) : bawahan hendaknya mengikuti dan mematuhi aturan yang mengaur organisasi

d. Unity of Command ( Kesatuan Komando) : setiap karyawan hanya meneriman intruksi dati atasan

e. Unity of Direction (Kesatuan Pengaruahan) : kegiatan dalam organisasi memiliki satu tujuan dah harus diarahkan oleh satu manajer dengan menggunakan rencana tunggal

f. Suboedination of Individual Interest to Generale Interest (Kepentingan Individu) : kepentingan individu tidak boleh emenggunakan nama kepentngan organisasi

g. Renumeration (Penggajian) : sistem penggajian harus fair baik karyawan masupun manajer

h. Centralization (Sentralisasi) : menejr bertanggung jawab terhadap organisasinya dan karyawan diberikan tanggung jawba untuk melaksanakan kerjanya.

i. Scalar Chain (Hirarki/garis wewenang) : sistemorganisasi turun dari manajer puncah sampai tingkat bawah

j. Order (Perimah,sumber daya) : harus memiliki kordinadi yang baik hingga siap kapan saja dan dimana saja biak di perlukan

k. Equity (Persamaan) : manajer dituntut harus ari dalam memperlakukan karyawan

1. Stability od Tonure od Personel (Stabilitas Staff) : perpindahan kerja yang tinggi harus di hindari karena membaut prganisasi berkerja secara tidak efisien

m. Initiative (Inisiatif) : karyawan di beri kebeban untuk berinisiatif melakukan pekerjaan

n. Esport he Corps : kerjsama tim dharus terus di dorong dan do leihara.

2) Max Weber (1864-1920)

Max Weber adalah seolah ahli sosisologi asal Jerman yang mengembangkan teori birokrasi, ia berpendapat bahwa suatu prganisasi yang terdiri atas ribuan anggota membutuhkan aturan yang jelas. Asapun organisasi yang ideal adalah birokrasi saata ktivitas dan tujuan diturunkan secara rasional dam pembagian kerjanya jelas. Birokrasi didasarkan pada aturan yang cukup rasional dan dapat di akai untuk mendesain struktur yang efisien dan keahlian Teknik serta evaluasi berdasarkan tuntutan prestasi. Model dan Teori Webwe di pahami kemduian di pakai dalam onegelolaan organisasi besar, seperti perusahaan multionasioal yang memiliki karyawan ribuan.

\section{Kelebihan dan Kekurangan Teori Organisasi Klasik}

Teori yang di kembangkan oleh Taylor merupakan sumbangan sistemasi yang sampai kini masih memiliki pengaruh yang cukup besar dari studi manajemen, sistemasi itu memberikan pandangan terhdap bidang bidang harus di analaisis untuk meningktakan efektivitas. Teori klasik juga di kritik karena ampak seakan lebih tepat untuk lingkungan stabil da tidak berubah, sedangkan lingkungan bisnis saat ini sangat cepat berubah sehingga validitas teori klasik sering di pertanyakan di perdebatkan.

1) Mary Parker Follet (1868-1933)

Teori Follet sedikit berbeda, diman aia memasukkan unsur mausia atau yang di kena dengan hubungan manusiawi ke dalam struktur organisasi dalam analisisnya. Ia yakin bahwa manajemen dan pekerja memiliki kepentingan yang sama dalam organisasi yang sama.

2) Chester I Baenard (1886-1961)

Chester I Barnard merupakan seorang direktur New Jersey Bell, yakni sebuah perusahaan telpon di Amerika Serikat pasa 1927, ia mengakui abhwa adanya kelompoknya 
informal dalam organisasi yang formal. Dan ia percaya bawha keseimbangan anatra tujuan organisasi dan idividu dapat di jaga bila manajer menagerti konsep wilayah penerimaan yakni pekerja yang menerima intruksi atasannya tanpa mempertanyakan ototritas manajemen. Hal ini tertuang dalam bukunya yang berjudul The Function of the Executive yang di terbitkan pada 1938 .

a. Aliran Perilaku

i. Pendekatan huhungan manusiasi (human relations)

Hubungan manusawi pada umumnya mengacu pada suasasana kerja yang berasal dari hubungan natara manajer dan karyawan.

ii. Sudi Hawthome

Studi ini adalah studi yang menguji adanya hubungan natara peneragan dan hal menunjang lainnya dalam peningktakan produktivitas yang memiliki hasil tidak menentu, namun peneliti menyebutkan bahwa kelompok dan pengaruh komunitas informal dalam kounitas formal memiliki pengaruh yang penitng dalam pembentukan motivasi kerja dan peningkatan produktivitas kerja,

iii. Kelebihan dan Kbeterbatasn Pendekatan hubungan manusaiawi

Aliran hubungan manusiawi menyadarkan penitngnya kebutuahan sosial yang dengan demikian di maksudkan dengan penyeimbangan konsep lama yakni mekenakan ekonomi manusia dan hal lainnya yang menunjuag kenyamnaan bekerja . meski demikian dalam teori ini analisis penelitian masih banyak menuai kontroversi, karenadi aggap bahwa teori ini tidak menjealsakn sepe uhnya perilaku mansuai yang sebenarnya, melainkan hanya melihat sisi ketia ia bekerja saja dengan mempertimbangkan beberapa factor pendukung lain seperti factor sosial, gaji, kemampuan kejra, budaya serta hal lainnya.

b. Pendekatan Ilmu Perilaku

Pendekatan manusia meneybabakan tumbuhnya pertumbuhan pendekatan baru yang lebih sering dikenal sebagai pendekatan ilmu perilaku. Para ahli dalam ilmu perilaku menggunakan metode dan konsep dari ilmu sosial, seperti sosiologi, psikolohi dan antrpolohi. Merkea mengembangkan kerangka analisis yang lebih kompleks di bandingkan dengan pendekatan hubungan manusia.

Aliran ilmu perilaku memberi masukan yang berarti terhdap pemahaman motivasi individu, perilaku kelompok, hubungan interpersonal dalam kerja dan pentingnya kejra untuk hidup mansuia. Meski demikia, terosi tersebut juga cukup komplek untuk manajer, mereka merekomendasikan satu ahli untuk membantu manajer yang mengalamani keseluitan dan memberi pendapatan yang paling baik diantara yang baik.

3) Pendekatan Kuantitatif

Pendekatan kuantitatif untuk manajemen mulai berkembang sejak Perang Dunia Ke II yang pada sat aitu Inggris memecahkan beberapa persoalan yang sangat komplkes dalam perang. Kemudian Inggris membentuk tim riset operasi (research operatipn) yang di pimpin oleh P.M.S Blackett yang terdiri dari ahli matematika, fisika dan ilmuwan lainnya. Dan kemudain Ameriak Serikat meniru dan membentuk tim riset ini untuk menghitung model model matematika yang di kembangkan. Teknik riest yang operasi dalam manejemen dikenal sebagai aliran manajemen science.

4) Pendekatan Kontingensi

Pendekatan kontingensi digunakan untuk menghubungkan anatra teori dan 
praktik laoangan, karen abiasanya implementasi teori berbeda dengen yang terjadi di lapangan sheingga harus memerlukan perhatian lingkungan sekitar yang juga memerlukan aplikasi konsep Teknik manajemen yang bebeda. Pendekatan jenis ini di pandang sebagai hubungan fungsional yang memiliki siste timbal balik, bila dan maka. Hubungan fungsional seperti ini memeiliki keterikatan anatra variabel yang satu dengan yang lainnya.

\section{KESIMPULAN}

Setiap hal mesti mengalami perubahan dan perkembangan tanpa terkecuali manajemen dan teori pendukungnya, teori dinilai memiliki dua sisi, yakni sisi yang membutuhkannya sebagai bentuk profesionalitas dan sisi yang menganggap bahwa teori yang ada hanya menghambat kerja yang berlangsung di lapangan. Padahal, sis yang pertama merupakan sisi yang benar,dimana tujuan adanya teori ialah membntuk professionalism manajemen karena manajemen pada dasarnya ialah ilmu dan seni yang di gunakan untuk memprediksi kemungkinan antara keterkaitan hal yang nyata atau fenomena dengan teori yang dikembangkan, yang demikian itu diharapkan mampu untuk mengurangi hal hal yang tidak di inginkan atau bahkan mal-praktik atau percobaan dalam pengoperasian hal hal yang berhubungan dengan pekerjaan. Perkembangan teori manajamen mengalami beberapa tahap, yakni diawali dengan teori manajemen kuno dan berkembang terus hingga saat ini, masing masing tahap memiliki masukan dan kekurangan yang kemudian terus di sempurnakan dnegan penelitian yang mendukung.

\section{DAFTAR PUSTAKA}

Cameron, Kim S., and Robert E. Quinn .2006. Diagnosing And Changing Organizational Culture: Based On The Competing Values Framework. Revised Edition. USA: Jossey-bass

Chaster I Bernard, 1938. The Functions of Executive, Cambridge- Mass: Harvard University press.

Donnely, Gibson dan Ivancevich. 1981. Fundamentals of Management. Plano, Texas: Business Publication.

Hanafi, Mamduh. 2008. Manajemen. Yogyakarta: UPP-AMP YKPN.

Henry Fayol, General And Industrial Management, London

Hugo Munsterberg, 1913. Psychology and Industrial Effeciency. Houghton Mifflin, New York,

James D.Money, 1974. The Principles of Organization, Edisi revisi. New York: Harper \& Brothers Publisers.

Koontz, Harold, Cyrril O’Donnel, dan Heinz Weihrich. 2004. Management.Singapore: McGraw Hill.

Kreitner, Robert, and Anggelo Kinicki. 2007. Organization Behavior. 7th Edition, New York; McGraw-Hall Inc.

Luthans, Fred, 2006. Organizational Behavior 10th Edition, New York, McGraw-Hill International Editions.

Peters, Thomas J, dan Robert H Waterman. 1982. In Search of Excellence. New York: Harper \& Row. 
Riggio, Ronald E., 2009. Introduction to Industri/Organizational Psychology. 5th Edition. New Jersey: Prentice Hall

Robbins, Stephen P, and Timoty A. Judge., 2009. Organizational Behavior. 13th Edition, New Jersey : Prentice-Hall International Inc.

Taylor, F.W. 1974. Scientifif Management, New York: Harper. 